\title{
The use of microsimulation models for the planning and management of metro systems
}

\author{
M. Ercolani, A. Placido, L. D'Acierno \& B. Montella \\ Department of Civil, Architectural and Environmental Engineering, \\ Federico II University of Naples, Italy
}

\begin{abstract}
The management of public transport for rebalancing the use of transportation systems is a useful tool for reducing negative externalities without excessively affecting zone accessibility. In this context, a rail or metro system can be a key element for producing a high-quality supply of public transport. Obviously, due to the great vulnerability of rail technology to system failures, it is necessary to develop suitable tools to identify rapidly, even with off-line procedures, the best operational strategies which minimise user discomfort produced by such failures. Hence, our proposal is to extend previous models proposed in the literature by considering travel demand as an outcome of a random variable and not only in terms of average values. The proposed approach is applied in the case of a real dimension metro network, considering a wider class of failure contexts.

Keywords: metro system management, rail passenger systems, microsimulation approach, travel demand analysis, capacity constraints, public transport.
\end{abstract}

\section{Introduction}

It is becoming increasingly necessary, especially in high density contexts, to develop useful strategies to improve liveability of large urban agglomerations and accessibility for people and goods. There are several measures which may be implemented by different kinds of decision-makers (such as local administrations, public transport operators and car manufacturers) to optimise the use of transportation systems, for instance by implementing pricing policies [1-3], by establishing restricted traffic zones [4], adopting ITS technologies to rationalise private car use $[5,6]$, improving public transport quality $[7,8]$ or implementing energy-saving strategies [9-12]. 
However, improvements in public transport performance, especially when there are reductions in economic resources, can be achieved by structuring the mobility system so as to use the rail/metro as a backbone and public road transport (buses and trolleybuses) to act as feeders (see, for instance, [13]. However, while rail/metro systems can be high-performing in terms of reduced headways between two successive convoys or maximum travel speeds, they are affected by great vulnerability in the event of disruption due mainly to the constrained driving technology. Indeed, in the case of system breakdowns, reestablishing regular rail schedules could yield high passenger delays, especially where there are not enough maintenance and/or bypass tracks for recovering faulty trains or when local rail regulations do not allow a faulty train to be coupled to a working one with passengers on board. Obviously, rail network managers have to plan their intervention strategies by taking into account effects of their decisions on travel demand.

However, it is worth noting that in the literature (as shown by [14-16]), until recently, rail system performance was still evaluated by neglecting effects on travel demand. Indeed, the first papers to consider that satisfying travel demand (i.e. passenger) requirements is the main purpose of a rail/metro system were [17], [18] and [19]. In this context, [20] and [21] proposed a trade-off between rail system performance and passenger quality of service. Likewise, [22] and [23] extended [20] and [21] by introducing capacity constraints of rail convoys for simulating explicitly that, especially in failure contexts, some trains might not have enough space to accommodate all passengers wishing to board.

In terms of rail emergency management, [24] and [25] proposed some methods for rescheduling rail services in the case of perturbations. Likewise, in order to analyse the deviation of real timetables from planned schedules, [26] proposed an off-line procedure for calibrating a predictive model, [27] provided a method to forecast delay propagations, and [28] proposed a tool for determining future evolutions of current conflicts in real-time conditions.

The aim of this paper is to extend previous works, especially those proposed by [22] and [23], by considering additional types of breakdowns (such as line failures) and analysing travel demand not only in terms of average values but also as an outcome of a random variable. However, in order to investigate the effects of any hypothesised intervention strategy, it is necessary to adopt a suitable simulation tool. In the literature, rail simulation tools which analyse interaction between infrastructure, rolling stock, signalling system and timetable can be classified, according to the assumption on the considered level of network detail, into macroscopic [29], [30], mesoscopic [31] and microscopic [32, 33]. However, although high calculation times could be required, our proposal is to adopt a microscopic approach in order to determine travel times of passengers in non-stationary contexts (i.e. two successive rail convoys may provide different levels of services such as values of residual capacity, travel times, etc.). Hence, this paper is organised as follows: Section 2 provides the simulation framework for simulating effects of intervention strategies; Section 3 describes the application of the proposed approach in the case of a real metro network; conclusions and research prospects are summarised in Section 4. 


\section{Simulating interaction among rail system components}

As shown by [23], the definition of the optimal intervention strategy in the case of rail/metro system failure can be formulated as:

$$
\hat{\boldsymbol{y}}=\underset{\boldsymbol{y} \in S_{\boldsymbol{y}}}{\arg \min } Z(\boldsymbol{y}, \boldsymbol{f}, \boldsymbol{t p}, \boldsymbol{r p}, \boldsymbol{u f})
$$

s.t.

$$
[\boldsymbol{t p}, \boldsymbol{r p}, \boldsymbol{u f}]^{\mathrm{T}}=\boldsymbol{\Pi}\left(\boldsymbol{y}, \boldsymbol{f}, \boldsymbol{t p}, \boldsymbol{r p}, \boldsymbol{u f}, \boldsymbol{i}^{0}, \boldsymbol{r}^{0}, \boldsymbol{s}^{0}, \boldsymbol{t}\right)
$$

where $\boldsymbol{y}$ is the intervention strategy vector, $\hat{\boldsymbol{y}}$ is the optimal value of $\boldsymbol{y} ; \boldsymbol{S}_{\boldsymbol{y}}$ is the feasibility set of $\boldsymbol{y} ; Z$ is the objective function to be minimised; $\boldsymbol{f}$ is the failure context vector; $\boldsymbol{t} \boldsymbol{p}$ is the transportation network performance vector; $\boldsymbol{r} \boldsymbol{p}$ is the rail system performance vector; $\boldsymbol{u} f$ is the user flow vector; $\Pi$ is the simulation function; $\boldsymbol{i}^{0}$ is the rail infrastructure vector in non-perturbed conditions; $\boldsymbol{r}^{0}$ is the rolling stock vector in non-perturbed conditions; $\boldsymbol{s}^{0}$ is the signalling system vector in non-perturbed conditions; $\boldsymbol{t}$ is the planned timetable vector.

In particular, as shown by [22] and [23], constraint (2) can be formulated by means of the interaction of four kinds of simulation models: a Failure Simulation Model (FSM), a Service Simulation Model (SeSM), a Supply Simulation Model (SuSM) and a Travel Demand Simulation Model (TDSM). In particular, the FSM can be formulated as:

$$
[\boldsymbol{i}, \boldsymbol{r}, \boldsymbol{s}]^{\mathrm{T}}=\boldsymbol{F S M}\left(\boldsymbol{i}^{0}, \boldsymbol{r}^{0}, \boldsymbol{s}^{0}, \boldsymbol{f}\right)
$$

and provides variation in performance of the rail/metro system (such as the reduction in maximum speed for a rail convoy or a track section) related to each possible breakdown, where $\boldsymbol{i}, \mathrm{r}$ and $\boldsymbol{s}$ are respectively rail infrastructure, rolling stock and signalling system vectors in perturbed conditions. Details of this kind of model can be found in [20] and [21]. The SeSM can be formulated as:

$$
r p=\operatorname{SeSM}(y, i, r, s, t, u f)
$$

and describes rail system performance depending on intervention strategy, rail infrastructures, rolling stock, signalling system, timetable and user flows on the network. This model is based on the solution of a system of differential equations, which can be tackled by means of suitable commercial software (such as OPENTRACK ${ }^{\circledR}$ software). The SuSM can be formulated as:

$$
\boldsymbol{t} \boldsymbol{p}=\operatorname{SuSM}(\boldsymbol{r p}, \boldsymbol{u f})
$$

and provides travel disutilities (expressed in terms of travel times and monetary costs) of users on all transportation systems in the analysed area. This model has as input data the output from service and travel demand simulation models. Details on this kind of model, indicated in the literature as cost functions, can be found in [34] and [35]. The TDSM can be formulated as:

$$
\boldsymbol{u f}=\boldsymbol{T D S M}(\boldsymbol{t p}, \boldsymbol{r p})
$$

and describes user choices which are conditioned by performance of transportation systems (i.e. output of service and supply simulation models). However, it is worth splitting the TDSM into two sub-models: a pre-platform model and an on-platform model. The Pre-Platform Travel Demand Simulation 
Model (PP-TDSM) describes user behaviour in the case of regular service and its outputs are user flows on each platform. The On-Platform Travel Demand Simulation Model (OP-TDSM) analyses with a FIFO (First In - First Out) approach whether passengers are able to board on the first arriving train or have to wait for the following rail convoys, and then provides boarding and alighting flows at each station for each convoy.

As shown in the literature, see for instance [34], the PP-TDSM can be implemented via a three-phase procedure: a travel demand estimation in terms of origins and destination of each trip (Origin-Destination Matrix) by means of four further sub-models: an emission model (which simulates the choice of whether or not to travel in a time period), a distribution model (which provides the choice of going towards a generic place), a mode choice model (which imitates the choice of travelling by private car, public transport or simply the pedestrian system) and a path choice model (which provides the route choice and, in the case of public transport, also line choice and related boarding/alighting at stops/stations); a survey of passenger flows at each station; a travel demand correction using demand model results and previous surveys. In particular, this phase consists in determining a new origin-destination matrix which is closest to the model estimation and which produces user flows closest to surveyed data.

However, since travel demand levels and rail/metro services do not have the same values throughout a day, a within-day dynamic approach must be adopted to implement the three phases mentioned above. Details on phases 1 and 2 can be found in [34]. Likewise details on phase 3 are provided by [36-38] and [39].

The interaction among the four simulation models in order to calculate the objective function value to be optimised, can be implemented as follows: for each failure context, by means of the FSM, it is possible to provide effects on the rail system in terms of reduced performance or unavailability of a train or a track section; the user flows on platforms, obtained by means of the PP-TDSM, are the result of user choices depending on performances of all transportation systems (i.e. the SuSM), including the rail/metro system (i.e. the SeSM); the performance of the rail system (the SeSM implemented by means of OPENTRACK ${ }^{\circledR}$ software) is related to intervention strategy, user flows on the network (i.e. the OP-TDSM) and the breakdown severity (outputs of the FSM); finally, the number of boarding and alighting passengers, evaluated by means of the OP-TDSM), is affected by passengers waiting on platforms (i.e. PP-TDSM), rolling stock features and rail/metro system performance (i.e. SeSM).

The main improvement of the proposed paper with respect to previous works of the same authors (i.e. [22] and [23] consists in adopting a different approach in determining origin destination matrices. Indeed, by analysing survey data related to a large time period, some statistical distribution functions describing counted flows may be determined. Hence, phase 3 (i.e. correction of travel demand) can be implemented not only by adopting average values over the period (i.e. by using the 50th percentiles of the travel demand distribution) but also by considering surveyed flows as random variables with known (calibrated) distribution and therefore by adopting different travel demand percentiles (in order to identify a higher safety factor). 


\section{Applications to a real metro line}

The proposed methodology was applied in the case of Line 1 of the Naples metro system (southern Italy). Conceptually, the line can be divided into three parts: the Piscinola-Dante section, $13.47 \mathrm{~km}$ long, consisting of 14 stations; the DanteUniversità section, $1.87 \mathrm{~km}$ long, consisting of three stations; the UniversitàGaribaldi section, $1.68 \mathrm{~km}$ long, consisting of two stations.

It is worth noting that until December 31st, 2013, the third section (i.e. Università-Garibaldi) was under construction and since the second section (Dante-Università) had two separate tunnels without any switch which enabled a metro convoy to change tracks, the metro services were performed as follows: a regular metro service between Piscinola and Dante (first section) ran on a double track section; a shuttle service between Dante and Università (second section) ran on just one of the two tracks of the section.

Indeed, a metro service along the whole line (i.e. Piscinola-Dante-Università) would have required the transit of a single rail convoy between Dante and Università (i.e. using only a single track). Therefore, this kind of service would have yielded a headway between two successive rail convoys of about 15 minutes, which was not compatible with the level of service required for a metro system. Hence, the operational enterprise adopted the double service option such that only the shuttle service would be constrained by the 15-minute headway, while the metro service (Piscinola-Dante) would allow headways of up to five minutes.

Now that the construction of the Università-Garibaldi section has been completed, a rail convoy is able to switch tracks in Garibaldi and the whole line between Piscinola and Garibaldi is able to yield headways consonant with the expectations of a metro service.

However, since the aim of this paper is to adopt surveyed data over a long period, our proposal is to analyse service conditions prior to December 31st, 2013. Hence, since the two previous services were completely independent and the train depot was next to Piscinola, we analyse only the metro service, neglecting the shuttle.

The application of the proposed methodology in the case of Line 1 can be divided into two phases: travel demand definition and implementation of the off-line procedure for determining the optimal intervention strategy in the case of metro system failure.

\subsection{Travel demand definition}

Travel demand was determined by analysing and processing turnstile data which provides for each station and for each time period of a day the number of crossing passengers. Obviously the station data do not allow the travel direction to be identified, except in the case of the terminus.

The turnstile data were extended over a nine-month time period. Hence, by neglecting data related to singular days such as holidays, pre-holiday and strikes, 
a substantial amount of data was obtained for each station and for each time period (there were five different time periods per day identified).

These data were adopted in order to determine the statistical distribution function which best describes the selected data, adopting the following approach:

- three kinds of distribution functions were considered: Gamma, Gumbel and Normal;

- for each station and for each time period, all three distribution functions were calibrated, i.e. distribution parameters were calculated so as to minimise differences between surveyed data and model data;

- for each calibrated distribution function (i.e. a function for each station and for each time period), the term $p$-value [40] was calculated. Indeed, this term allows us to measure how close the statistical distribution is to the physical phenomenon;

- finally, we selected the Gamma function as the best since its $p$-values are almost always higher than those of the other distributions. Obviously, the selection is related only to the functional form while function parameters differ for each station and each time period.

Table 1: P-value terms in the case of Gamma distribution function.

\begin{tabular}{|c|c|c|c|c|c|c|c|c|c|c|c|c|c|c|}
\hline & ST & ST & ST & ST & ST & ST & ST & ST & ST & ST & ST & ST & ST & ST \\
\hline & 01 & 02 & 03 & 04 & 05 & 06 & $\mathbf{0 7}$ & 08 & 09 & 10 & 11 & 12 & 13 & 14 \\
\hline TP1 & 0.16 & 0.00 & 0.70 & 0.98 & 0.79 & 0.63 & 0.37 & 0.07 & 0.11 & 0.20 & 0.16 & 0.05 & 0.62 & 0.12 \\
\hline TP2 & 0.68 & 0.50 & 0.37 & 0.35 & 0.92 & 0.37 & 0.81 & 0.00 & 0.95 & 0.90 & 0.25 & 0.01 & 0.85 & 0.62 \\
\hline TP3 & 0.22 & 0.41 & 0.08 & 0.04 & 0.66 & 0.74 & 0.82 & 0.52 & 0.71 & 0.60 & 0.99 & 0.13 & 0.27 & 0.97 \\
\hline TP4 & 0.84 & 0.66 & 0.47 & 0.85 & 0.57 & 0.74 & 0.30 & 0.70 & 0.52 & 0.34 & 0.29 & 0.08 & 0.63 & 0.07 \\
\hline TP5 & 0.55 & 0.85 & 0.12 & 0.17 & 0.28 & 0.64 & 0.99 & 0.20 & 0.26 & 0.90 & 0.66 & 0.16 & 0.75 & 0.03 \\
\hline
\end{tabular}

Table 2: P-value terms in the case of Gumbel distribution function.

\begin{tabular}{|c|c|c|c|c|c|c|c|c|c|c|c|c|c|c|}
\hline & $\begin{array}{l}\text { ST } \\
01\end{array}$ & $\begin{array}{l}\text { ST } \\
02\end{array}$ & $\begin{array}{l}\text { ST } \\
\mathbf{0 3}\end{array}$ & $\begin{array}{l}\text { ST } \\
\text { 04 }\end{array}$ & $\begin{array}{l}\text { ST } \\
05\end{array}$ & $\begin{array}{l}\text { ST } \\
06\end{array}$ & $\begin{array}{l}\text { ST } \\
\text { 07 }\end{array}$ & $\begin{array}{l}\text { ST } \\
\text { 08 }\end{array}$ & $\begin{array}{l}\text { ST } \\
09\end{array}$ & $\begin{array}{l}\text { ST } \\
10\end{array}$ & $\begin{array}{l}\text { ST } \\
11\end{array}$ & $\begin{array}{l}\text { ST } \\
12\end{array}$ & $\begin{array}{l}\text { ST } \\
13\end{array}$ & $\begin{array}{l}\text { ST } \\
14\end{array}$ \\
\hline TP1 & 0.03 & 0.00 & 0.45 & 0.99 & 0.84 & 0.55 & 0.46 & 0.02 & 0.07 & 0.05 & 0.06 & 0.08 & 0.26 & 0.13 \\
\hline TP2 & 0.18 & 0.60 & 0.15 & 0.10 & 0.56 & 0.06 & 0.82 & 0.00 & 0.60 & 1.00 & 0.07 & 0.05 & 0.19 & 0.07 \\
\hline TP3 & 0.06 & 0.59 & 0.15 & 0.01 & 0.38 & 0.44 & 0.99 & 0.14 & 0.26 & 0.25 & 0.98 & 0.34 & 0.69 & 0.79 \\
\hline TP4 & 0.71 & 0.70 & 0.27 & 0.45 & 0.32 & 0.56 & 0.23 & 0.28 & 0.19 & 0.07 & 0.09 & 0.10 & 0.11 & 0.01 \\
\hline TP5 & 0.43 & 0.64 & 0.12 & 0.21 & 0.23 & 0.67 & 0.99 & 0.25 & 0.05 & 0.67 & 0.78 & 0.08 & 0.18 & 0.07 \\
\hline
\end{tabular}

Table 3: P-value terms in the case of Normal distribution function.

\begin{tabular}{|c|c|c|c|c|c|c|c|c|c|c|c|c|c|c|}
\hline & ST & ST & ST & ST & ST & ST & ST & ST & ST & ST & ST & ST & ST & ST \\
\hline & 01 & 02 & 03 & 04 & 05 & 06 & 07 & 08 & 09 & 10 & 11 & 12 & 13 & 14 \\
\hline TP1 & 0.28 & 0.00 & 0.63 & 0.24 & 0.14 & 0.17 & 0.08 & 0.28 & 0.11 & 0.77 & 0.74 & 0.00 & 0.69 & 0.09 \\
\hline TP2 & 0.92 & 0.36 & 0.53 & 0.69 & 0.90 & 0.70 & 0.72 & 0.02 & 0.66 & 0.35 & 0.80 & 0.00 & 0.87 & 0.61 \\
\hline TP3 & 0.29 & 0.14 & 0.02 & 0.27 & 0.42 & 0.55 & 0.33 & 0.90 & 0.99 & 0.62 & 0.33 & 0.01 & 0.10 & 0.63 \\
\hline TP4 & 0.62 & 0.43 & 0.71 & 0.83 & 0.55 & 0.44 & 0.60 & 0.38 & 0.75 & 0.69 & 0.88 & 0.01 & 0.83 & 0.22 \\
\hline TP5 & 0.02 & 0.10 & 0.00 & 0.45 & 0.01 & 0.07 & 0.21 & 0.03 & 0.73 & 0.99 & 0.20 & 0.19 & 0.97 & 0.01 \\
\hline
\end{tabular}

Tables 1-3 provide values of the p-value term for each station (ST) and for each time period (TP) in the case of the three statistical distribution functions. The Gamma function has p-values higher than the Gumbel function in 49 of 70 cases (i.e. in $70 \%$ of cases) and than the Normal function in 40 of 70 cases (i.e. $57 \%$ of cases). 
However, having fixed the statistical distributions, we selected three kinds of data to be adopted in the procedure of travel demand correction. In particular, we considered three demand levels: the 50th percentile, corresponding to the traditional approach based on the average condition; the 85th percentile, corresponding to a moderately high value of travel demand; the 95th percentile, corresponding to an exceptionally high value of travel demand.

These sets of data were adopted to implement the procedures described in detail by [36-38] and [39]. Figure 1 provides the Gamma distribution function by highlighting the three considered levels of travel demand.

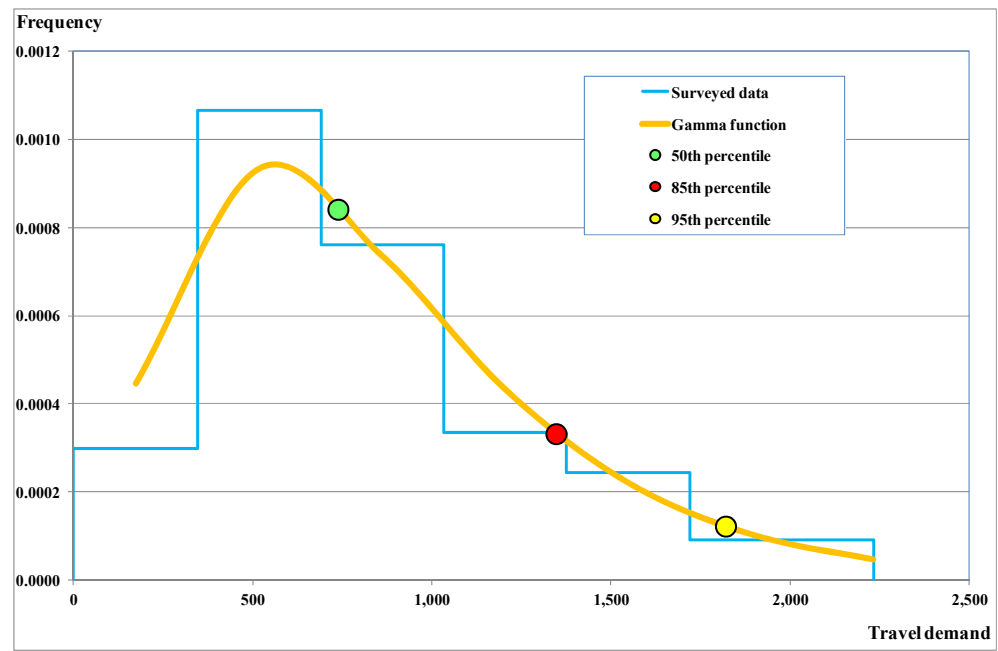

Figure 1: Gamma function distribution and demand levels in the case of station no. 1 (Piscinola) in time period no. 5 (19.00-23.30).

\subsection{Identification of optimal intervention strategies}

In order to identify the optimal operation strategy in the case of metro service failure it is necessary to: implement a regular service scenario to be used as a reference scenario for estimating the worsening of service conditions; identify rail system elements, in terms of infrastructure, rolling stock and/or signalling system affected by the considered breakdown; identify all feasible intervention strategies for improving service conditions; evaluate for each intervention strategy the effect on travel demand in terms of total generalised user costs; identify the intervention strategy which best minimises user discomfort.

The proposed methodology was applied in the case of the following three failure events:

- at Dante station (the terminus far away from the depot) a breakdown occurs in the ATP (Automatic Train Protection) system of the train performing run 801 (i.e. the run which starts from Dante at 7.16 a.m.). Hence, the convoy is forced to travel at a maximum speed of $45 \mathrm{~km} / \mathrm{h}$; 
- in the track section between Piscinola and Colli Aminei, the ATP system of the infrastructure breaks down for the whole day and hence all trains have to respect the speed limit of $45 \mathrm{~km} / \mathrm{h}$;

- at Colli Aminei station, the train performing run 602 (i.e. the run which starts from Piscinola at 7.37 a.m.) experiences a breakdown in the door closing system. Hence, the train is not allowed to travel with passengers on board.

Importantly, all results have been obtained by considering three different travel demand levels, i.e. 50th, 85th and 95th percentiles. Moreover, since due to maintenance and regulation enforcements there are 36 traction units available per day, the service enterprise is forced to adopt, in the case of operations with 9 convoys, 6 tripleheader convoys (i.e. convoys with 3 traction units) and 3 doubleheader convoys (i.e. convoys with 2 traction units), with respectively the following capacities: 1251 and 834 passengers. Hence, due to the randomness of the breakdown phenomena, it is necessary to simulate three kinds of convoy sequences, i.e. 3-3-2, 3-2-3 and 2-3-3. Indeed, it cannot be established a priori which train will be the first to start in the daily service and/or which train will undergo the breakdown.

Table 4 provides user costs in the case of different fleet compositions and different travel demand levels.

Table 4: Daily user generalised costs [in Euros] in the case of regular service.

\begin{tabular}{cccc}
\hline Travel demand level & Fleet 3-3-2 & Fleet 3-2-3 & Fleet 2-3-3 \\
\hline 50th percentile & 172,102 & 172,102 & 172,102 \\
85th percentile & 222,919 & 222,919 & 223,263 \\
95th percentile & 258,406 & 258,293 & 259,017 \\
\hline
\end{tabular}

Table 5: Daily user generalised cost [in Euros] in the case of train failure.

\begin{tabular}{ccccc}
\hline Intervention strategy & Travel demand level & Fleet 3-3-2 & Fleet 3-2-3 & Fleet 2-3-3 \\
\hline Maintenance of the & 50th percentile & 172,146 & 172,146 & 172,146 \\
faulty train (depot) & 85th percentile & 222,979 & 222,979 & 223,324 \\
with a new & 95th percentile & 258,477 & 258,365 & 259,088 \\
replacement convoy & 50th percentile & 197,148 & 197,973 & 197,946 \\
\hline Maintenance of the & 85th percentile & 258,062 & 259,027 & 258,516 \\
$\begin{array}{c}\text { without any } \\
\text { replacement convoy }\end{array}$ & 95th percentile & 303,250 & 304,142 & 302,450 \\
\hline The faulty train & 50th percentile & 174,370 & 174,370 & 174,370 \\
continues the services & 85th percentile & 225,836 & 225,836 & 226,121 \\
throughout the whole & 95th percentile & 261,404 & 261,308 & 261,898 \\
\hline day & & & &
\end{tabular}

In the first failure context, i.e. a convoy failure, one of three intervention strategies may be implemented (as listed in Table 5):

1) the train completes the whole service until the last terminus (i.e. Piscinola) and then it is sent to the depot. A new convoy (replacement) will continue the service;

2) the train completes the whole service until the last terminus (i.e. Piscinola) and then it is driven to the depot. No convoy will replace the faulty train;

3) the faulty train will continue the service throughout the day. 
On analysing the simulation results of intervention strategies it emerges that the replacement of a faulty train with an efficient new convoy is always the best operational strategy. Obviously, this is possible only if there are additional convoys. Hence, this methodology allows quantification of the cost and benefits of having additional trains (the costs are the purchase costs).

Moreover, the simulations show that if there are no additional convoys for replacement operations, the best strategy consists in using the faulty train because the speed limit $(45 \mathrm{~km} / \mathrm{h})$ allows a fair service to be attained in any event (user discomfort is reduced).

In the second failure context, i.e. a signalling system failure, it is not possible to implement suitable intervention strategies for reducing user discomfort. However, in this case estimation of user disutilities can be useful for quantifying the costs and benefits of carrying out urgent maintenance operations to restore the regular service or, in the planning/design phases, the increase in redundancy of technological components to reduce failure probabilities. However, Table 6 shows that the increase in user generalised costs is always lower than $2 \%$.

Finally, in the third case, i.e. a breakdown which reduces the functionality but not performance of a convoy, we generally have two feasible strategies: leaving the train on the line (i.e. at the station platform) and trying to repair the damage; or making passengers alight on the platform, driving the faulty train onto the maintenance track and putting a replacement convoy (from the depot) in operation.

Since repair times are generally unpredictable, we compare effects in the case of an a-priori unknown repair time of 10 minutes, 20 minutes and 30 minutes. In this case results were estimated only in the case of Fleet 3-3-2 because only a doubleheader convoy can be replaced on the maintenance track next to Colli Aminei station.

Table 7 shows that only if the time required to repair the train is lower than 10 minutes is it worth waiting at the station. In all other cases it is best to remove the faulty train from service and request a replacement convoy.

Table 6: Daily user generalised costs [in Euros] in the case of signalling system failure.

\begin{tabular}{cccc}
\hline Travel demand level & Fleet 3-3-2 & Fleet 3-2-3 & Fleet 2-3-3 \\
\hline 50th percentile & 175,419 & 175,419 & 175,419 \\
85th percentile & 227,254 & 227,254 & 227,540 \\
95th percentile & 263,058 & 262,977 & 263,607 \\
\hline
\end{tabular}

Table 7: Daily user generalised costs [in Euros] in the case of different repair strategies.

\begin{tabular}{ccccc}
\hline $\begin{array}{c}\text { Travel } \\
\text { demand } \\
\text { level }\end{array}$ & $\begin{array}{c}\text { Drive the faulty } \\
\text { train onto the } \\
\text { maintenance track }\end{array}$ & $\begin{array}{c}\text { Repair the } \\
\text { damage } \\
(\mathbf{1 0} \text { min) }\end{array}$ & $\begin{array}{c}\text { Repair the } \\
\text { damage } \\
(\mathbf{2 0} \text { min) }\end{array}$ & $\begin{array}{c}\text { Repair the } \\
\text { damage } \\
\text { (30 min) }\end{array}$ \\
\hline 50th percentile & 175,885 & 173,002 & 177,938 & 186,624 \\
85th percentile & 227,942 & 224,128 & 230,602 & 242,444 \\
95th percentile & 264,298 & 259,832 & 267,183 & 281,202 \\
\hline
\end{tabular}




\section{Conclusions and research prospects}

In this paper previous contributions by the same authors were extended to consider additional types of breakdowns (such as line failures) and analyse travel demand not only in terms of average values but as an outcome of a random variable. The numerical results show that the use of simulation models based on a microscopic approach allows user discomfort due to rail system breakdown to be estimated in detail, thereby suggesting the best operational or investment strategy to be implemented. In terms of future research we propose to apply the above methodology in other contexts both in terms of different rail networks and in terms of breakdown type.

\section{Acknowledgement}

This paper is partially supported under research project PON - DiGITAL PATTERN grant no. PON01_01268.

\section{References}

[1] Gallo, M., A fuel surcharge policy for reducing road traffic greenhouse gas emissions. Transport Policy, 18(2), pp. 413-424, 2011.

[2] Gallo, M., D’Acierno, L. \& Montella, B., A multilayer model to simulate cruising for parking in urban areas. Transport Policy, 18(5), pp. 735-744, 2011.

[3] D’Acierno, L., Ciccarelli, R., Montella, B. \& Gallo, M., A multimodal multiuser approach for analysing pricing policies in urban contexts. Journal of Applied Sciences, 11(4), pp. 599-609, 2011.

[4] Biggiero, L., The impact of transport management on local activities system: The role of limited traffic zones. WIT Transactions on the Built Environment, 138, 2014.

[5] Ben-Elia, E., Di Pace, R., Bifulco, G.N. \& Shiftan, Y., The impact of travel information's accuracy on route-choice. Transportation Research Part $C$, 26, pp. 146-159, 2013.

[6] Bifulco, G.N., Pariota, L., Simonelli, F. \& Di Pace, R., Development and testing of a fully adaptive cruise control system. Transportation Research Part C, 29, pp. 156-170, 2013.

[7] Gallo, M., D’Acierno, L. \& Montella, B., A multimodal approach to bus frequency design. WIT Transactions on the Built Environment, 116, pp. 193-204, 2011.

[8] Gallo, M., Montella, B. \& D’Acierno, L., The transit network design problem with elastic demand and internalisation of external costs: An application to rail frequency optimisation. Transportation Research Part $C$, 19(6), pp. 1276-1305, 2011.

[9] Wang, Y., De Schutter, B., Ning, B., Groot, N. \& van den Boom, T.J.J., Optimal trajectory planning for trains using mixed integer linear programming. Proc. of the 14th IEEE Conference on Intelligent Transportation Systems (ITSC), pp. 1598-1603, 2011. 
[10] Corapi, G., Sanzari, D., De Martinis, V., D’Acierno, L. \& Montella, B., A simulation-based approach for evaluating train operating costs under different signalling systems. WIT Transactions on the Built Environment, 130, pp. 149-161, 2013.

[11] De Martinis, V., Gallo, M. \& D'Acierno, L., Estimating the benefits of energy-efficient train driving strategies: a model calibration with real data. WIT Transactions on the Built Environment, 130, pp. 201-211, 2013.

[12] Corapi, G, De Martinis, V., Placido, A. \& De Luca, G., Impacts of Energy Saving Strategies (ESSs) on rail services and related effects on travel demand. WIT Transactions on the Built Environment, 135, 2014.

[13] D’Acierno, L., Gallo, M., Biggiero, L. \& Montella, B., Replanning public transport services in the case of budget reductions. WIT Transactions on the Built Environment, 138, 2014.

[14] Gibson, S., Allocation of capacity in the rail industry. Utilities Policy, 11(1), pp. 39-42, 2003.

[15] Abril, M., Barber, F., Ingolotti, L., Salido, M.A., Tormos, P. \& Lova, A., An assessment of railway capacity. Transportation Research Part E, 44(5), pp. 774-806, 2008.

[16] Lindner, T., Applicability of the analytical UIC Code 406 compression method for evaluating line and station capacity. Journal of Rail Transport Planning \& Management, 1(1), pp. 49-57, 2011.

[17] Hamdouch, Y., Ho, H.W., Sumalee, A. \& Wang, G., Schedule-based transit assignment model with vehicle capacity and seat availability. Transportation Research Part B, 45(10), pp. 1805-1830, 2011.

[18] Kanai, S., Shiina, K., Harada, S. \& Tomii, N., An optimal delay management algorithm from passengers' viewpoints considering the whole railway network. Journal of Rail Transport Planning \& Management, 1(1), pp. 25-37, 2011.

[19] Zheng, Y., Zhang, Z., Xu, B. \& Wang, L., Carrying capacity reliability of railway networks. Journal of Transportation Systems Engineering and Information Technology, 11(4), pp. 16-21, 2011.

[20] Mazzeo, A., Mazzocca, N., Nardone, R., D’Acierno, L., Montella, B., Punzo, V., Quaglietta, E., Lamberti, I. \& Marmo, P., An integrated approach for availability and QoS evaluation in railway systems. Lecture Notes in Computer Science, 6894, pp. 171-184, 2011.

[21] Quaglietta, E., D’Acierno, L., Punzo, V., Nardone, R. \& Mazzocca, N., A simulation framework for supporting design and real-time decisional phases in railway systems. Proc. of the 14th IEEE Conference on Intelligent Transportation Systems (ITSC), pp. 846-851, 2011.

[22] D'Acierno, L., Gallo, M., Montella, B. \& Placido, A., Analysis of the interaction between travel demand and rail capacity constraints. WIT Transactions on the Built Environment, 128, pp. 197-207, 2012.

[23] D'Acierno, L., Gallo, M., Montella, B. \& Placido, A., The definition of a model framework for managing rail systems in the case of breakdowns. Proc. of the 16th IEEE Conference on Intelligent Transportation Systems (ITSC), pp. 1059-1064, 2013. 
[24] Corman, F., D'Ariano, A., Hansen, I.A. \& Pacciarelli, D., Optimal multi-class rescheduling of railway traffic. Journal of Rail Transport Planning \& Management, 1(1), pp. 14-24, 2011.

[25] van den Boom, T.J.J., Kersbergen, B. \& De Schutter, B., Structured modeling, analysis, and control of complex railway operations. Proc. of the 51st IEEE Conference on Decision and Control, pp. 7366-7371, 2012.

[26] Hansen, I.A., Goverde, R.M.P. \& van der Meer, D.J., Online train delay recognition and running time prediction. Proc. of the 13th International IEEE Conference on Intelligent Transportation Systems (ITSC), pp. 1783-1788, 2010.

[27] Goverde, R.M.P., A delay propagation algorithm for large-scale railway traffic networks. Transportation Research Part C, 18(3), pp. 269-287, 2010.

[28] Goverde, R.M.P. \& Meng, L., Advanced monitoring and management information of railway operations. Journal of Rail Transport Planning \& Management, 1(2), pp. 69-79, 2011.

[29] Kettner, M. \& Sewcyk, B., A model for transportation planning and railway network evaluation. Proc. of the 9th World Congress on Intelligent Transport Systems, Chicago (IL), USA, 2002.

[30] Prinz, R., Sewcyk, B. \& Kettner, M., NEMO: Network Evaluation Model for the Austrian railroad (ÖBB). Eisenbahntechnische Rundschau, 50(3), pp. 117-121, 2001.

[31] Marinov, M. \& Viegas, J., A mesoscopic simulation modelling methodology for analyzing and evaluating freight train operations in a rail network. Simulation Modelling Practice and Theory, 19(1), pp. 516-539.

[32] Nash, A. \& Huerlimann, D., Railroad simulation using OpenTrack. Computers in Railways, 9, pp. 45-54, 2004.

[33] Siefer, T. \& Radtke, A., Railway simulation: key for better operation and optimal use of infrastructure. Proc. of the 1st International Seminar on Railway Operations Modelling and Analysis, Delft, The Netherlands, 2005.

[34] Cascetta, E., Transportation systems analysis: models and applications. Springer: New York (NY), USA, 2009.

[35] D'Acierno, L., Cartenì, A. \& Montella, B., Estimation of urban traffic conditions using an Automatic Vehicle Location (AVL) System. European Journal of Operational Research, 196(2), pp. 719-736, 2009.

[36] Cartenì, A., Updating demand vectors using traffic counts on congested networks: A real case application. WIT Transactions on the Built Environment, 96, pp. 211-221, 2007.

[37] Cipriani, E., Florian, M., Mahut, M. \& Nigro, M., A gradient approximation approach for adjusting temporal origin-destination matrices. Transportation Research Part C, 19(2), pp. 270-282, 2011.

[38] Cascetta, E., Papola, A., Marzano, V., Simonelli, F. \& Vitiello, I., Quasi-dynamic estimation of o-d flows from traffic counts: Formulation, statistical validation and performance analysis on real data. Transportation Research Part B, 55, pp. 171-187, 2013. 
[39] Cipriani, E., Nigro, M., Fusco, G. \& Colombaroni, C., Effectiveness of link and path information on simultaneous adjustment of dynamic O-D demand matrix. European Transport Research Review, DOI: 10.1007/s12544-0130115-z, 2013.

[40] Nuzzo R., Scientific method: Statistical errors. Nature, 506(7487), pp. 150-152, 2014. 